\title{
Downregulated Tim-3 expression is responsible for the incidence and development of colorectal cancer
}

\author{
PING ZHANG ${ }^{1}$, YAN WANG ${ }^{2}$, XUE-RONG LIU $^{3}$, SHI-RU HONG $^{4}$ and JIAN YAO ${ }^{1}$ \\ Departments of ${ }^{1}$ Integrated Traditional Chinese Medicine and Western Medicine, ${ }^{2}$ Hematology, ${ }^{3}$ Oncology and \\ ${ }^{4}$ Respiratory Medicine, The First Affiliated Hospital of Harbin Medical University, Harbin, Heilongjiang 150001, P.R. China
}

Received April 26, 2016; Accepted August 8, 2017

DOI: $10.3892 / \mathrm{ol} .2018 .8697$

\begin{abstract}
The present study aimed to investigate the role of $\mathrm{T}$ cell immunoglobulin domain and mucin-3 (Tim-3) in its gene and protein forms in colorectal cancer (CRC), and to verify the significance of Tim-3 expression in patients with CRC. A prospective analysis of 258 patients with CRC and 246 normal controls was conducted between December 2012 and June 2015. Intestinal samples were collected, including of CRC tissues, paracancerous tissues and normal colon mucosa tissues. Peripheral venous blood samples were also collected. Polymerase chain reaction (PCR) amplification, reverse transcription-quantitative PCR (RT-qPCR) and western blot analysis was performed for the detection and evaluation of Tim-3 gene and protein in various tissues. PCR analysis indicated that the $\mathrm{T}$ and $\mathrm{G}$ alleles of $-882 \mathrm{C} / \mathrm{T}$ and $4259 \mathrm{~T} / \mathrm{G}$ are associated with a significantly increased risk of CRC. Following the confirmation of Tim-3 expression in CRC tissues, RT-qPCR detection and western blot analysis revealed clear downregulation of Tim-3 mRNA and protein expression in the blood and tissue samples obtained from patients with $\mathrm{CRC}$, as compared with in the corresponding control samples. Similar trends of decreased Tim-3 mRNA levels and protein expression were observed in CRC tissues compared with in the paracancerous and the normal colon mucosa tissues. In addition, the mRNA and protein expression levels in the paracancerous tissues were lower than those in the normal colon mucosa tissues. Furthermore, significantly lower Tim-3 mRNA levels were observed in patients with a tumor size $>5 \mathrm{~cm}$, a poor differentiation degree, higher tumor-node-metastasis stage (stage III-IV), and lymph node and distant metastasis. Collectively, genetic changes to Tim-3, expressed as polymorphisms in Tim-3, and decreased
\end{abstract}

Correspondence to: Dr Jian Yao, Department of Integrated Traditional Chinese Medicine and Western Medicine, The First Affiliated Hospital of Harbin Medical University, 23 Post Street, Nangang, Harbin, Heilongjiang 150001, P.R. China

E-mail: yjbeauty15@163.com

Key words: T cell immunoglobulin domain and mucin-3, colorectal cancer, protein expression, mRNA level
mRNA/protein expression may be partially responsible for the incidence and development of CRC.

\section{Introduction}

Colorectal cancer (CRC) is a cancer that originates from parts of the large intestine (such as the colon or rectum) due to the abnormal proliferation of tumor cells, which have the ability to invade and migrate to other sites in the body $(1,2)$. CRC is a major cause of cancer-associated mortality worldwide, and is estimated to be the third most commonly diagnosed cancer, as well as the leading cause of cancer-associated mortality, in females and males (3). The incidence and mortality rates of CRC vary substantially based on different countries and ethnicities, with the rates in developing countries and in African-Americans being relatively higher than those in developed countries and in Asians, which may be associated with the disproportionately low socioeconomic status (4,5). A rapid increase in the incidence and mortality rate of CRC in China has been witnessed over the past few decades $(6,7)$. In previous years, a large number of patients with CRC were diagnosed at an advanced stage; however, due to the widespread implementation of colonoscopy screening and improvements in treatment $(8,9)$, diagnosis has now improved. However, prognostic outcomes remain poor, with a 5-year survival rate of $<15 \%$ (10), as over $50 \%$ of all diagnosed cases are likely to develop metastases, and the majority of these patients have unresectable tumors $(11,12)$. Notably, major non-risk factors associated with the development of CRC include age, gender, diet, alcohol consumption, obesity, smoking, lack of physical exercise, diabetes and atherosclerosis, economic status and methods of diagnosis (13-15). Furthermore, at the cellular level, CRC is a biologically heterogeneous disease, and the progressive accumulation of genetic changes and epigenetic alterations may perform critical roles in inducing the pathological changes involved in transforming normal colonic epithelium into malignant tumors (16-18).

Proteins in the $\mathrm{T}$ cell immunoglobulin domain and mucin (Tim) family are transmembrane glycoproteins that possess common structural motifs, including immunoglobulin V, mucin, transmembrane and cytoplasmic domains $(19,20)$. Members of the Tim family, which were initially recognized as specific surface molecules of T helper (Th)1 and Th2 cells, can provide co-stimulatory signals targeting the functional 
role of Th1 and Th2 cells regarding the regulation mechanism of differentiation $(21,22)$. The Tim family encodes eight members in mice (Tim-1 through Tim-8), which are located at 11B1.1, and gene loci of the three members in humans (Tim-1,-3 and -4) mapped on chromosome 5q33.2 (23). Members of the family are critical for Th1- and Th2-mediated immunity, and they are implicated in various autoimmune and allergic-associated diseases, cancer types and viral infections in humans (24-26). Tim-3 is selectively and highly expressed by well-differentiated Th1 cells, but not by Th2 cells (27). Following interaction with its ligand, galectin-9, Tim-3 may induce a positive or negative stimulus for the activation and differentiation of $\mathrm{T}$ cells, so exerting immunomodulatory properties $(28,29)$. Similarly, Tim-3 may stimulate tumor cells to escape immunosurveillance. Previous evidence has documented the inhibitory effect of Tim-3 on Th1-mediated immunity $(30,31)$. Furthermore, Tim-3 can cause innate immune cells, including macrophages/monocytes and natural killer (NK) cells, to inhibit tissue damaging immune responses (32) and can release inflammatory mediators, such as tumor necrosis factor- $\alpha$ and interleukin- 6 , to participate in the occurrence and development of inflammation $(33,34)$. The mechanisms underlying Tim-3-mediated T cell activity in mediating immune- or inflammation-associated diseases are relatively clear; however, it remains to be clarified whether Tim-3 is expressed on tumor cells or tissues in patients with CRC. In addition, the mechanisms by which Tim-3 is involved in human CRC remain unclear. In the present study, the genetic mutations and expression activities of Tim-3, and how these affect the clinical features of patients with CRC, were investigated in order to clarify the role of Tim-3 in the incidence and development of CRC.

\section{Materials and methods}

Ethical statement. The present study was approved by the Ethics Committee of The First Affiliated Hospital of Harbin Medical University (Harbin, China). All procedures performed in the present study involving humans were conducted in accordance with the ethical standards of the institutional and/or national research committee in the First Affiliated Hospital of Harbin Medical University (Harbin, China), and with The Declaration of Helsinki (1964) and its later amendments (35). All patients enrolled in the present study were Chinese. The experimental objectives and details regarding the procedures involved in the present study were presented to all patients enrolled, and corresponding written informed consent was provided prior to the initiation of the experiments.

Patients. A prospective study was conducted based on the collection and analysis of a total of 258 patients diagnosed with CRC between December 2012 and June 2015 at The First Affiliated Hospital of Harbin Medical University. All patients were inquired in detail in terms of medical history and examined carefully prior to inclusion in the present study, and the diagnosis of CRC was determined following consideration of the physical condition of each patient, the results of clinical laboratory tests and X-ray imaging. Of all the patients included, 136 were male and 122 were female, all ranging between 28 and 72 years old, with a mean age of $57.46 \pm 10.23$ years. The inclusion criteria were as follows: i) Patients were confirmed to have CRC histologically by pathologists blinded to the clinical outcome; ii) patients did not receive any prior preoperative treatment over the past 6 months, including chemotherapy, radiotherapy or Traditional Chinese Medicine treatment; iii) patients had no history of other malignant tumor types; iv) patients were willing to be involved in the study and could cooperate with the experimental procedures to provide complete clinical data. The Dukes' (36) and tumor-node-metastasis (TNM) staging systems, recommended by the Union for International Cancer Control and the American Joint Committee on Cancer (7th Ed.) (37), were applied for the histological pattern classification of included patients. During the same period at the same hospital, 246 cases of normal controls from healthy volunteers who were examined were collected. Of these, 140 were male and 106 were female, ranging between 26 and 78 years of age (mean, 56.50 \pm 12.00 years). The controls were confirmed to have no history of CRC or other malignant tumor types, and could provide complete clinical information relevant to the experiment.

Separation of peripheral blood mononuclear cells (PBMCs) and sample collection/processing. After $12 \mathrm{~h}$ of overnight fasting, peripheral venous blood samples $(10 \mathrm{ml})$ were drawn from each patient via clean venipuncture in the early morning, and collected in heparin-anticoagulant tubes. Collected blood was diluted (1:1) and a $20 \mathrm{ml}$ suspension was prepared. Subsequent to adding the Ficoll separating liquid (Tianjin Haoyang Biological Products Science and Technology Co., Ltd., Tianjin, China) to the centrifuge tube, Ficoll density gradient centrifugation was performed $\left(447 \mathrm{x} \mathrm{g}, 20 \mathrm{~min}, 18-20^{\circ} \mathrm{C}\right)$. The liquids were then divided into four layers from top to bottom. A straw was gently inserted into the annular white cloud layer (the second layer) to absorb the PBMCs. PBS (5:1) was added to the PBMCs, followed by centrifugation $(1,500 \mathrm{rpm} / \mathrm{min}, 15 \mathrm{~min}$, $\left.18-20^{\circ} \mathrm{C}\right)$. The supernatant was discarded, and the centrifugation procedure was repeated. High purity PBMCs were obtained subsequent to discarding the supernatant. Mononuclear cell purity of $\geq 80 \%$ was achieved through density gradient centrifugation and the adherence method (38).

In addition, intestinal samples were collected from each patient during surgery, including CRC radical cancerous tissues, paracancerous tissues $(<2.0 \mathrm{~cm}$ beyond the cancer tissue) and normal colon mucosa tissues $(>5.0 \mathrm{~cm}$ beyond the cancer tissue). All blood and tissue specimens were rapidly placed into liquid nitrogen and maintained at $-80^{\circ} \mathrm{C}$ for $10 \mathrm{~min}$. All tissue samples were prepared for the extraction of RNA and proteins for polymerase chain reaction (PCR) amplification, reverse transcription-quantitative PCR (RT-qPCR) and western blot analysis. Furthermore, immunohistochemical staining was performed following paraffin embedding and sectioning, according to the manufacturer's protocols. All related experimental procedures were performed in accordance with the protocol provided by the manufacturer (Boster Bioengineering Co., Ltd., Wuhan, China). Subsequently, mouse anti-human TIM-3 monoclonal primary antibody (dilution ratio, 1:100; cat. no. 1315, Sigma-Aldrich; Merck KGaA, Darmstadt, Germany) was added to the sections overnight at $4^{\circ} \mathrm{C}$. The samples were then maintained at room temperature for $30 \mathrm{~min}$, 
Table I. Baseline characteristics of 258 patients with colorectal cancer.

mRNA levels of Tim-3 (n)

\begin{tabular}{|c|c|c|c|c|}
\hline \multirow{2}{*}{ Variables } & \\
\hline & Low levels & High levels & Z-value & P-value \\
\hline Total & 148 & 110 & & \\
\hline \multicolumn{5}{|l|}{ Gender } \\
\hline Male & 75 & 61 & -0.709 & 0.448 \\
\hline Female & 73 & 49 & & \\
\hline \multicolumn{5}{|l|}{ Age } \\
\hline$<60$ years & 64 & 59 & -1.650 & 0.099 \\
\hline$\geq 60$ years & 84 & 51 & & \\
\hline \multicolumn{5}{|l|}{ Tumor size } \\
\hline$\leq 5 \mathrm{~cm}$ & 66 & 65 & -2.299 & 0.022 \\
\hline$>5 \mathrm{~cm}$ & 82 & 45 & & \\
\hline \multicolumn{5}{|l|}{ Family history } \\
\hline With & 68 & 57 & -0.932 & 0.352 \\
\hline Without & 80 & 53 & & \\
\hline \multicolumn{5}{|l|}{ Differentiation } \\
\hline Well-moderate & 59 & 58 & -2.048 & 0.041 \\
\hline Poor & 89 & 52 & & \\
\hline \multicolumn{5}{|l|}{ TNM stages } \\
\hline I-II & 58 & 62 & -2.730 & 0.006 \\
\hline III-IV & 90 & 48 & & \\
\hline \multicolumn{5}{|c|}{ Lymph node metastasis } \\
\hline With & 88 & 50 & -2.226 & 0.026 \\
\hline Without & 60 & 60 & & \\
\hline \multicolumn{5}{|l|}{ Distant metastasis } \\
\hline With & 78 & 43 & -2.163 & 0.031 \\
\hline Without & 70 & 67 & & \\
\hline \multicolumn{5}{|l|}{ Clinical stages } \\
\hline I-II & 78 & 63 & -0.728 & 0.467 \\
\hline III-IV & 70 & 47 & & \\
\hline
\end{tabular}

Tim-3, T cell immunoglobulin domain and mucin-3; TNM, tumor-node-metastasis. Nonparametric test was used for statistical analysis.

followed by washing with PBS, and incubation with a rabbit anti-mouse secondary antibody (cat. no: abs20002; Absin Biotechnology Co., Ltd. Shanghai, China) for $30 \mathrm{~min}$ at $37^{\circ} \mathrm{C}$. After further washing with PBS, DAB staining was performed and the samples were mounted after another hematoxylin counter-staining and visualized on an inverted microscope (IX71, Olympus, Tokyo, Japan). In the course of the experiment, PBS was used as in place of the primary antibody as a negative control. Positive cells were defined as brown or yellow brown granules. The pathologists and laboratory personnel involved were blinded to the case/control status of all collected and extracted samples.

PCR amplification. Genomic DNA was isolated from the collected whole blood samples using the Wizard Genomic DNA Purification Kit ${ }^{\circledR}$ (Promega Corporation, Madison, WI, USA), according to the manufacturer's protocol. Genotyping of Tim-3 polymorphisms was performed with a PCR-restriction fragment length polymorphism. According to the sequences of human $\beta$-actin (GI:168480144) and Tim-3 (GI:354681988) obtained from the National Center for Biotechnology Information GenBank (https://www.ncbi.nlm.nih.gov/), PREMIER Primer 5.0 software (PREMIER Biosoft, Palo Alto, CA, USA) was used for the design of specific primers. The capture probe sequences were as follows: Tim-3 forward, 5'-CCAAATCCCAGGCAT AAT-3' and reverse, 5'-AAGCGA-CAACCCAAAGGT-3'; $\beta$-actin forward, 5'-CGAAACTACCT-TCAACTCCATC-3' and reverse, 5'-AGTGATCTCCTTCTGCATCCT-3'. PCR was performed in a total volume of $15 \mu \mathrm{l}$ : DNA template $(0.5 \mu \mathrm{l})$, Taq DNA polymerase (1.25 unit; Appligene-Oncor, Heidelberg, Germany), 10X Taq buffer (1.5 $\mu$; Shanghai Pharmaceutical Industries Co., Ltd., Shanghai, China), $2.5 \mathrm{mmol} / 1 \mathrm{dNTP}$ mix $(1.0 \mu \mathrm{l})$, upstream/downstream primers (per $0.2 \mu \mathrm{l})$ and sterile double-distilled water added up to a final volume of $15 \mu \mathrm{l}$. The 
Table II. Distribution of the frequency and distribution of $-882 \mathrm{C} / \mathrm{T}$ and $4259 \mathrm{~T} / \mathrm{G}$ alleles in the $\mathrm{T}$ cell immunoglobulin domain and mucin-3 gene between the case and control groups.

\begin{tabular}{|c|c|c|c|c|c|}
\hline Site & $\begin{array}{l}\text { Case group } \\
\quad(\mathrm{n}=258)\end{array}$ & $\begin{array}{l}\text { Control group } \\
\quad(\mathrm{n}=246)\end{array}$ & $\chi^{2}$ & P-value & OR $(95 \% \mathrm{CI})$ \\
\hline \multicolumn{6}{|l|}{$-882 \mathrm{C} / \mathrm{T}$} \\
\hline $\mathrm{CC}$ & 150 & 168 & & & 1.00 \\
\hline $\mathrm{CT}$ & 86 & 74 & 1.844 & 0.175 & $1.302(0.889-1.905)$ \\
\hline TT & 22 & 4 & 12.024 & 0.001 & $6.160(2.076-18.282)$ \\
\hline $\mathrm{CT}+\mathrm{TT}$ & 108 & 196 & 8.680 & 0.003 & $0.617(0.447-0.852)$ \\
\hline $\mathrm{C}$ & 386 & 410 & & & 1.00 \\
\hline $\mathrm{T}$ & 130 & 82 & 11.026 & 0.001 & $1.684(1.236-2.295)$ \\
\hline \multicolumn{6}{|l|}{$4259 \mathrm{~T} / \mathrm{G}$} \\
\hline TT & 148 & 172 & & & 1.00 \\
\hline TG & 88 & 69 & 4.047 & 0.044 & $1.482(1.009-2.177)$ \\
\hline GG & 22 & 5 & 12.368 & $<0.001$ & $5.114(1.889-13.839)$ \\
\hline $\mathrm{TG}+\mathrm{GG}$ & 110 & 194 & 6.513 & 0.011 & $0.659(0.478-0.908)$ \\
\hline $\mathrm{T}$ & 384 & 413 & & & 1.00 \\
\hline G & 132 & 79 & 13.804 & $<0.001$ & $1.797(1.316-2.454)$ \\
\hline
\end{tabular}

OR, odds ratio; 95\% CI, 95\% confidence interval.

PCR reaction was conducted under the following conditions: Pre-degeneration at $95^{\circ} \mathrm{C}$ for 4 min, followed by 20 cycles of $95^{\circ} \mathrm{C}$ for $30 \mathrm{sec}, 68^{\circ} \mathrm{C}$ for $45 \mathrm{sec}$ and $72^{\circ} \mathrm{C}$ for $60 \mathrm{sec}$, and then another 20 cycles of $95^{\circ} \mathrm{C}$ for $30 \mathrm{sec}, 58^{\circ} \mathrm{C}$ for $30 \mathrm{sec}$ and $72^{\circ} \mathrm{C}$ for $40 \mathrm{sec}$. Following the completion of PCR, $3 \mu \mathrm{l}$ of the PCR products were separated and analyzed via $2 \%$ agarose gel and SDS-PAGE. PCR products were digested overnight with XhoI and PstI to identify the Tim-3-882C/T and 4259G/T genotypes. All PCR products were confirmed with DNA sequencing in an automatic DNA sequencer ABI 3100 Avant (Applied Biosystems; Thermo Fisher Scientific, Inc., Waltham, MA, USA), and the single nucleotide polymorphism genotypes were auto-analyzed using Sequence Detection System 1.4.0 software (Applied Biosystems; Thermo Fisher Scientific, Inc.).

RT-qPCR detection. Total RNA extraction from blood samples was performed using a TRIzol ${ }^{\circledR}$ kit (Invitrogen; Thermo Fisher Scientific, Inc.), according to the manufacturer's protocol. Total RNA was purified with a NanoVue ${ }^{\mathrm{TM}}$ Plus spectrophotometer (GE Healthcare, Chicago, IL, USA) at wavelengths of 260 and $280 \mathrm{~nm}$. The extracted RNA from each sample was then reverse transcribed into cDNA via an RT-PCR assay (Qiagen $\mathrm{GmbH}$, Hilden, Germany), according to the manufacturer's protocol, followed by preservation at $-20^{\circ} \mathrm{C}$. The relative expression of Tim-3 levels was measured using RT-PCR, as described previously (39), and the TaqMan-based qPCR reagent kit was provided by Exiqon A/S (Vedbaek, Denmark). The primer sequences were as aforementioned. The reaction conditions were: Pre-denaturing for $5 \mathrm{~min}$ at $95^{\circ} \mathrm{C}$, followed by $10 \mathrm{sec}$ at $95^{\circ} \mathrm{C}$ and $1 \mathrm{~min}$ at $60^{\circ} \mathrm{C}$, for 40 cycles in total. $\beta$-actin was used as the internal control, and the $2^{-\Delta \Delta C q}$ method (40) was applied for the detection of Tim-3 and the corresponding control. Experiments were performed three times to stabilize the final results.
Western blot analysis. Total protein was extracted using a Total Protein Extraction kit (Nanjing KeyGen Biotech Co., Ltd., Nanjing, China) in accordance with the manufacturer's protocol, and the standard bicinchoninic acid (BCA) method was used for protein determination, as previously reported (41). Subsequent to calculating the amount of $\mathrm{BCA}$ detection reagent according to the number of samples, $50 \mu \mathrm{g}$ total protein was resolved by $10 \%$ SDS-PAGE and transferred to a polyvinylidene fluoride membrane, which was blocked for $1 \mathrm{~h}$ at room temperature with 5\% skimmed milk. All antibodies used in this experiment were purchased from Abcam (Cambridge, MA, USA). Subsequently, the rabbit anti-human AGR2 polyclonal (dilution, 1:1,000; catalog no. ab76473) and rabbit anti-human $\beta$-actin polyclonal (dilution, 1:200; catalog no. ab6276) primary antibodies were added and incubated overnight at $4^{\circ} \mathrm{C}$ on an agitating table. Primary antibodies were purchased from Abcam. On the second day, following washing in PBS at $37^{\circ} \mathrm{C}$ for $1 \mathrm{~h}$ (three times) and three washes with TBS-Tween-20 buffer, a horseradish peroxidase-labeled goat anti-rabbit secondary antibody (catalog no. ab181658; dilution, 1:10,000; Abcam) was added and incubated at $37^{\circ} \mathrm{C}$ for $1 \mathrm{~h}$, followed by membrane rinsing (three times, 5 min each). Positive bands were developed and visualised by autoradiography following the addition of a chemiluminescent reagent (Sigma-Aldrich; Merck KGaA). Quantitative analysis (Quantity one analysis system software; Bio-Rad Laboratories, Inc., Hercules, CA, USA) was performed by estimating the gray value ratios of the target protein Tim-3 and the reference protein $\beta$-actin.

Statistical analysis. All data files were processed using SPSS 17.0 statistical software (SPSS, Inc., Chicago, IL, USA). Measurement data are presented as the mean \pm standard deviation and categorical data were tested using t-test and nonparametric test. All the tests in the present study were two-sided. Furthermore, 

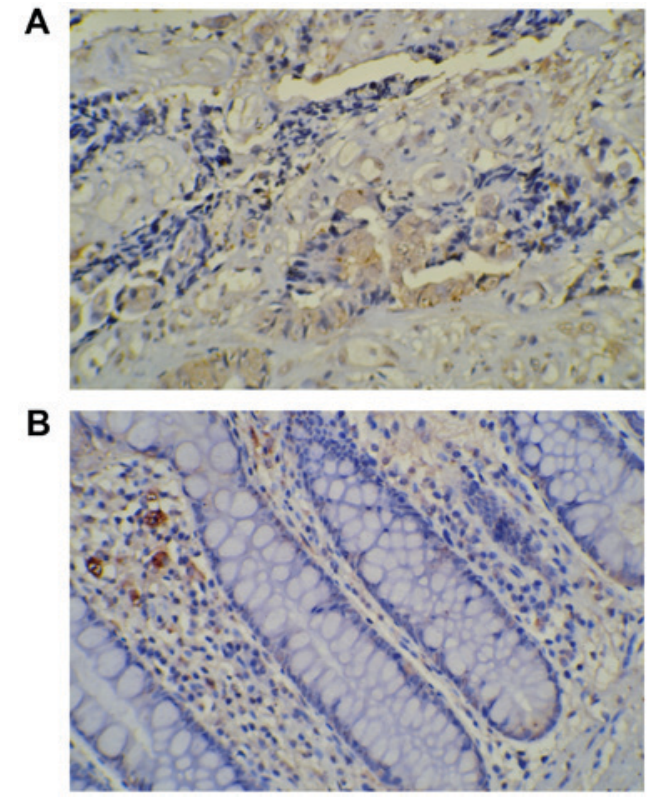

Figure 1. Immunohistochemical staining results regarding the positive signal of Tim 3 protein and the expression of Tim 3. Tim 3 was localized in the cytoplasm and nucleus (yellow or brown granules), largely expressed in colon carcinoma tissues and normal colon mucosa tissues, and rarely expressed in the cell membrane. (A) Colon carcinoma tissues; (B) normal colon mucosa tissues. Tim 3, T cell immunoglobulin domain and mucin 3 .

Hardy-Weinberg equilibrium was used to confirm the genotypes and allele frequencies. Spearman's correlation analysis was also performed to investigate the correlation between Tim-3 mRNA and protein expression levels. $\mathrm{P}<0.05$ was considered to indicate a statistically significant difference.

\section{Results}

Baseline characteristics of patients. As listed in Table I, there were 136 males and 122 females in the case group, with a mean age of $57.46 \pm 10.23$ years. There were 246 normal controls, consisting of 140 males and 106 females, with a mean age of $56.50 \pm 12.00$ years. No evident statistical significance was detected regarding the gender and age distribution between groups $(\mathrm{P}>0.05)$, which were comparable. There were 123 cases of patients aged $<60$ years, and the numbers of patients with a detected tumor size of $\leq 5$ and $>5 \mathrm{~cm}$ were 131 and 127 , respectively. In addition, 125 patients had a family history of CRC. Histological grade classification results revealed 117 cases well-moderate differentiation and 141 cases of poor differentiation. Lymph node metastasis and distant metastasis were also detected and recorded; 138 patients had lymph node metastasis and 121 patients had distant metastasis. A total of 120 patients were TNM stage I/II and 138 patients were TNM stage III/IV. Finally, 141 of the cases were clinical stage I or II and 117 cases were clinical stage III or IV. Immunohistochemistry indicated that Tim-3 staining (yellow or brown granules) was predominantly localized in the cytoplasm and nucleus (Fig. 1).

Tim-3 gene expression in CRC cases and corresponding controls. A total of three different genotypes were detected in the Tim-3-882C/T and 4259T/G, namely CC, CT and TT and TT, TG and GG, respectively (Table II). In the control group,
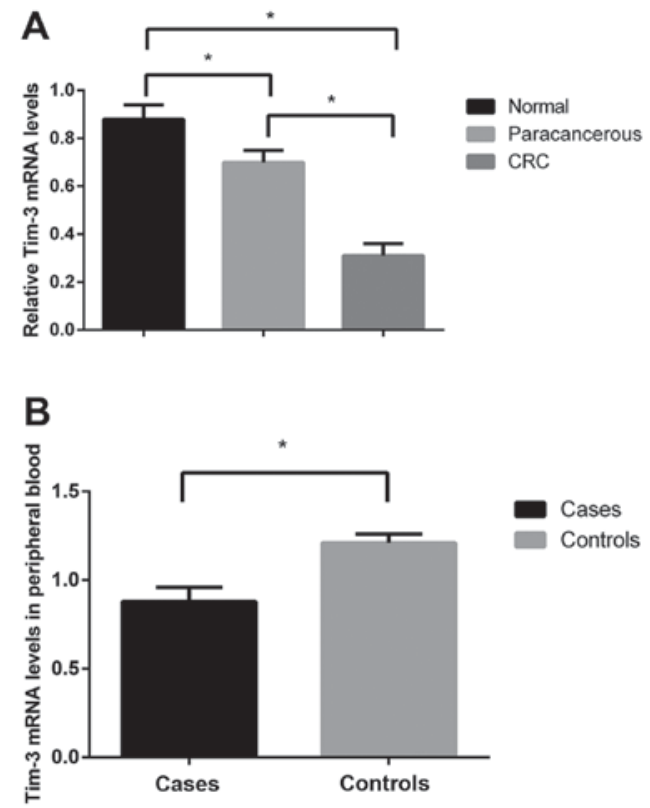

Figure 2.mRNA levels of Tim 3 measured by reverse transcription-quantitative polymerase chain reaction. (A) Compared with paracancerous tissues and normal colon mucosa tissues, the levels of Tim 3 mRNA were significantly lower in CRC tissues. (B) There mRNA levels of Tim 3 in monocytes from peripheral blood of patients with CRC were significantly lower compared with controls. ${ }^{*} \mathrm{P}<0.05$. CRC, colorectal cancer; Tim $3, \mathrm{~T}$ cell immunoglobulin domain and mucin 3 .

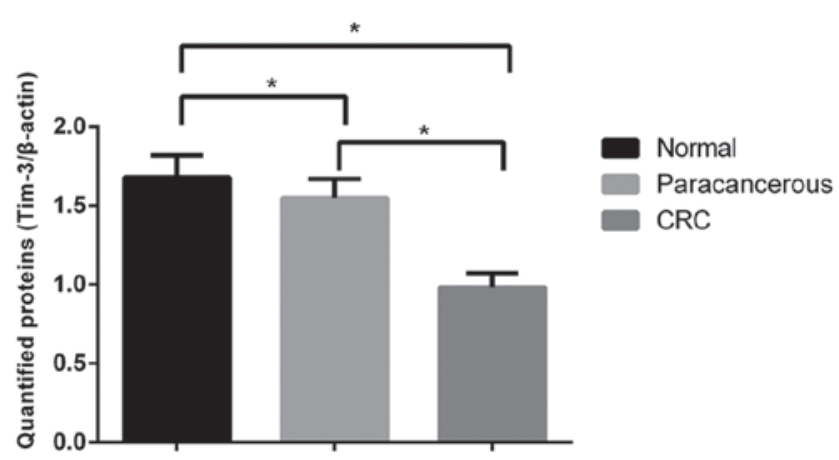

Figure 3. Protein expression of Tim 3 was measured by western blot analysis. A reduced expression of Tim 3 protein was observed in CRC tissues compared with normal colon mucosa tissues and paracancerous tissues. Paracancerous tissues also had a lower expression of Tim 3 compared with normal colon mucosa tissues. ${ }^{*} \mathrm{P}<0.05$. CRC, colorectal cancer; Tim 3 , T cell immunoglobulin domain and mucin 3.

the $\chi^{2}$ test revealed that the genotypes and allele frequencies of $-882 \mathrm{C} / \mathrm{T}$ and $4259 \mathrm{~T} / \mathrm{G}$ conformed to the Hardy-Weinberg equilibrium. The genotype distribution and allele frequency of $-882 \mathrm{C} / \mathrm{T}$ and $4259 \mathrm{~T} / \mathrm{G}$ polymorphisms were significantly different compared with the case group and the control group (all $\mathrm{P}<0.05$ ), with the exception of the genotype distribution comparison of $\mathrm{CC} / \mathrm{CT}$ between the groups $(\mathrm{P}>0.05)$. Notably, the $\mathrm{T}$ and $\mathrm{G}$ alleles of $-882 \mathrm{C} / \mathrm{T}$ and $4259 \mathrm{G} / \mathrm{T}$ were associated with a significantly increased risk of CRC [-882C/T: Odds ratio $(\mathrm{OR})=1.684$; $95 \%$ confidence interval $(\mathrm{CI}), 1.236-2.295$; $\mathrm{P}=0.001 ;$ 4259T/G: $\mathrm{OR}=1.797 ;$ 95\% CI, 1.316-2.454; $\mathrm{P}<0.001]$.

Tim-3 mRNA and protein expression in CRC specimens and PBMCs. Overall, 148 cases had low Tim-3 expression levels 
and 110 had high expression levels. RT-qPCR detection and western blot analysis revealed clearly decreased levels of Tim-3 mRNA and its protein expression in monocytes from the peripheral blood and tissue samples from patients with CRC, as compared with the blood samples of the normal controls, as well as with the normal colon mucosa tissues and paracancerous tissues from patients (mRNA levels: $0.78 \pm 0.09$ vs. $1.32 \pm 0.06$; protein expression: $0.34 \pm 0.05$ vs. $0.73 \pm 0.06$ vs. $0.88 \pm 0.07$; all $\mathrm{P}<0.05$ ), respectively. Furthermore, in a comparison of Tim-3 protein expression levels between the paracancerous and the normal colon mucosa tissues, the former had lower expression levels when compared with the latter $(\mathrm{P}<0.05)$ (Figs. 2 and 3).

Association between Tim-3 polymorphisms and mRNA/protein expression. A significant positive correlation was also observed between Tim-3 mRNA and protein expression levels, with a Spearman's correlation coefficient of $0.315(\mathrm{P}=0.029)$. In the polymorphism group, a significant negative correlation was observed between Tim-3 polymorphisms and the mRNA expression levels, with a Spearman's correlation coefficient of $-0.635(\mathrm{P}<0.001)$.

Association between Tim-3 mRNA levels and CRC clinicopathological parameters. The associations between Tim-3 mRNA levels and the clinicopathological parameters of CRC are presented in Table I. Tim-3 mRNA levels were revealed to be significantly associated with tumor size, differentiation, TNM stage, lymph node metastasis and distant metastasis (all $\mathrm{P}<0.05)$. However, no significant associations were observed regarding other clinicopathological parameters, including gender, age, family history and clinical stage (all $\mathrm{P}>0.05$ ). These results suggest that significantly lower Tim-3 mRNA levels could be detected in patients with a tumor size $>5 \mathrm{~cm}$, poor differentiation degree, higher TNM stage (stage III and IV), and with lymph node and distant metastasis.

\section{Discussion}

Immune homeostasis is an equilibrium state formed and maintained by the body's immune system interacting with the environment and components of the immune system, and by the activation of $\mathrm{T}$ lymphocytes and the polarization of Th1/Th2, immune cells are involved in the regulation of immune homeostasis $(42,43)$. The Tim gene family, mainly expressed on the surface of immune cells, has a regulatory effect in tumor immune surveillance and immune escape (44). A number of previous studies have demonstrated that once the microenvironment of immune homeostasis is damaged, it may promote the occurrence of immunological injury in disease progression, including sepsis, inflammatory bowel disease, tuberculosis and various malignant tumors (45-48). The Tim-3 protein performs critical roles in regulating immune function subsequent to binding with its ligands, which may be regarded as a novel target for human cancer treatment $(29,49,50)$.

Prior evidence has revealed the expression of Tim-3 in numerous types of malignant tumors, including renal cell carcinoma and melanoma $(51,52)$; however, few studies have focused on detecting the expression of Tim-3 in CRC. In the present study, immunohistochemical detection revealed Tim-3 expression in the cytoplasm and nuclei of normal gastric mucosa and gastric carcinoma tissues, confirming that Tim-3 is expressed in patients with CRC and that it may be critical for the development of CRC. To clarify the role of Tim-3 in CRC, PCR amplification, RT-qPCR and western blot analyses were conducted to investigate the roles of its associated genes and proteins. Firstly, PCR amplification verified that polymorphisms of Tim-3 were detectable in patients with CRC, and that Tim-3 mRNA was detectable via RT-qPCR. The results indicated that the $\mathrm{T}$ and $\mathrm{G}$ alleles of $-882 \mathrm{C} / \mathrm{T}$ and $4259 \mathrm{G} / \mathrm{T}$ may be risk factors for the development of CRC. Secondly, Tim-3 mRNA and protein expression of the incorporated tissues were detected by RT-qPCR and western blot analysis, respectively, and the protein expression levels results were concordant with those of the Tim-3 mRNA levels. Therefore, it was hypothesized that Tim-3 polymorphisms associated with low expression levels of Tim-3 may be strongly associated with CRC. This hypothesis was verified by correlation analysis, wherein a negative association between Tim-3 polymorphisms and mRNA levels was identified, indicating that Tim-3 polymorphisms may decrease the expression levels of Tim-3, thus affecting the biological function of this protein, and be involved in the development of CRC.

A possible mechanism associated with the aforementioned hypothesis may be that Tim-3 expressed on tumor cells has diverse tumorigenic activities contributing to tumor-initiating and tumor-promoting activities. Previous studies also demonstrated that Tim-3 signals may promote a significant increase in interferon- $\gamma($ IFN- $\gamma)$, and that suppressed expression of Tim-3 could inhibit the role of IFN- $\gamma$ in antitumor immunity $(53,54)$. However, the mechanisms by which Tim-3 regulates immune factors, cytokines and other parameters must be identified and verified in future studies. In the long-term process of tumor formation, tumor cells and the body's immune cells interact and mutually adapt with each other steadily, and the functions of immune cells change from the monitoring to the removal of tumor cells $(55,56)$, to interact and support each other, and finally to promote tumor immune tolerance, angiogenesis, invasion and metastasis through the release of cytokines, vascular endothelial growth factor and matrix degrading enzymes (57). Thus, the inhibition of Tim-3 expression using antagonists, or the interference of relevant signal pathways, may be a possible method for effecting tumor suppression. Recently, Gao et al (58) proposed that the Tim-3-574G/T polymorphism is associated with an increased risk of digestive system cancer and other cancer (such as hepatocellular cancer and renal cell carcinoma) in the Chinese Han population. da Silva et al (52) also revealed that Tim-3 may be considered as a NK cell exhaustion marker in advanced melanoma, and supported the use of Tim-3-targeted therapies to restore the antitumor immunity in patients with advanced melanoma (52). It is therefore essential that treatment with anti-Tim-3 suppress its tumorigenic effects, which requires confirmation in in vitro and in vivo settings. The present study revealed that clinicopathological parameters, including tumor size, differentiation degree, TNM stage, lymph node metastasis and distant metastasis, may be effected by Tim-3 and thus responsible for the development of CRC. However, Tim-3 expression was not determined to be associated with gender, age, family history or clinical stage, which may be accepted only cautiously due to 
the restricted inclusion of samples and different backgrounds, including lifestyle, economic status and family history. With regard to the aforementioned results, and in combination with those of previous studies, the results suggested that patients with a tumor size $>5 \mathrm{~cm}$, poor differentiation degree, higher TNM stage (stage III and IV), and with lymph node and distant metastasis may have a significantly increased risk of CRC compared with patients without these characteristics, which in turn strengthened the importance of monitoring patients clinicopathological parameters in screening for CRC.

The present study had several limitations. Firstly, an in-depth study of the underlying mechanisms of the role of Tim-3 in the incidence and development of CRC should be conducted, in order to improve systematic understanding of this topic. Secondly, the present study used a relatively small sample size, which may have an effect on the wider clinical applications. Thirdly, the mechanism by which decreased Tim-3 expression promotes CRC cell invasion and metastasis requires further study. Finally, the results of the current study require confirmation through in vivo and in vitro experimental models with long-term follow-up in cases and trials to verify the potential effect of targeted therapies based on Tim-3 in CRC, and in other types of malignant tumors. The present study hypothesized that the inhibition of Tim-3 with a specific antagonist may have an anticancer effect on the development of CRC.

In summary, Tim-3 expression is primarily located in in the cytoplasm and nucleus, genetic changes of Tim-3 in the blood and tissue samples are expressed as polymorphisms, and decreased mRNA and protein expression may be partially responsible for the incidence and development of CRC. Reduced Tim-3 expression, induced by genetic polymorphisms of Tim-3, may promote CRC invasion and metastasis.

\section{References}

1. Richter J, Rudeck S, Kretz AL, Kramer K, Just S, Henne-Bruns D, Hillenbrand A, Leithauser F, Lemke J and Knippschild U: Decreased CK1ठ expression predicts prolonged survival in colorectal cancer patients. Tumour Biol 27: 8731-8739, 2016.

2. Day LW and Velayos F: Colorectal cancer of the elderly. Curr Treat Options Gastroenterol 12: 269-282, 2014.

3. Burada F, Nicoli ER, Ciurea ME, Uscatu DC, Ioana M and Gheonea DI: Autophagy in colorectal cancer: An important switch from physiology to pathology. World J Gastrointest Oncol 7: 271-284, 2015.

4. Pibiri F, Kittles RA, Sandler RS, Keku TO, Kupfer SS, Xicola RM, Llor X and Ellis NA: Genetic variation in vitamin D-related genes and risk of colorectal cancer in African Americans. Cancer Causes Control 25: 561-570, 2014.

5. Kumar K, Brim H, Giardiello F, Smoot DT, Nouraie M, Lee EL and Ashktorab H: Distinct BRAF (V600E) and KRAS mutations in high microsatellite instability sporadic colorectal cancer in African Americans. Clin Cancer Res 15: 1155-1161, 2009.

6. Sun K, Deng HJ, Lei ST, Dong JQ and Li GX: miRNA-338-3p suppresses cell growth of human colorectal carcinoma by targeting smoothened. World J Gastroenterol 19: 2197-2207, 2013.

7. Sun K, Wang W, Zeng JJ, Wu CT, Lei ST and Li GX: MicroRNA-221 inhibits CDKN1C/p57 expression in human colorectal carcinoma. Acta Pharmacol Sin 32: 375-384, 2011.

8. Triantafillidis JK, Vagianos C and Malgarinos G: Colonoscopy in colorectal cancer screening: Current aspects. Indian J Surg Oncol 6: 237-250, 2015.

9. Malkomes P, Lunger I, Luetticke A, Oppermann E, Haetscher N, Serve H, Holzer K, Bechstein WO and Rieger MA: Selective AKT inhibition by MK-2206 represses colorectal cancer-initiating stem cells. Ann Surg Oncol 23: 2849-2857, 2016.
10. Nedrebø BS, Søreide K, Eriksen MT, Kvaløy JT, Søreide JA and Kørner H: Excess mortality after curative surgery for colorectal cancer changes over time and differs for patients with colon versus rectal cancer. Acta Oncol 52: 933-940, 2013.

11. van Gestel YR, de Hingh IH, van Herk-Sukel MP, van Erning FN, Beerepoot LV, Wijsman JH, Slooter GD, Rutten HJ, Creemers GJ and Lemmens VE: Patterns of metachronous metastases after curative treatment of colorectal cancer. Cancer Epidemiol 38: 448-454, 2014.

12. Matsumoto T, Hasegawa S, Matsumoto S, Horimatsu T, Okoshi K, Yamada M, Kawada K and Sakai Y: Overcoming the challenges of primary tumor management in patients with metastatic colorectal cancer unresectable for cure and an asymptomatic primary tumor. Dis Colon Rectum 57: 679-686, 2014

13. Vissers PA, Thong MS, Pouwer F, den Oudsten BL, Nieuwenhuijzen GA and van de Poll-Franse LV: The individual and combined effect of colorectal cancer and diabetes on health-related quality of life and sexual functioning: Results from the PROFILES registry. Support Care Cancer 22: 3071-3079, 2014

14. Jeon JY and Meyerhardt JA: Can we change the past for colorectal cancer patients and how do we move forward? Cancer 120: 1450-1452, 2014

15. Kontou N, Psaltopoulou T, Soupos N, Polychronopoulos E, Xinopoulos D, Linos A and Panagiotakos DB: Metabolic syndrome and colorectal cancer: The protective role of Mediterranean diet-a case-control study. Angiology 63: 390-396, 2012.

16. Okugawa Y, Grady WM and Goel A: Epigenetic alterations in colorectal cancer: Emerging Biomarkers. Gastroenterology 149: 1204-1225.e12, 2015.

17. Mundade R, Imperiale TF, Prabhu L, Loehrer PJ and Lu T: Genetic pathways, prevention, and treatment of sporadic colorectal cancer. Oncoscience 1: 400-406, 2014.

18. Zoratto F, Rossi L, Verrico M, Papa A, Basso E, Zullo A, Tomao L, Romiti A, Lo Russo G and Tomao S: Focus on genetic and epigenetic events of colorectal cancer pathogenesis: Implications for molecular diagnosis. Tumour Biol 35: 6195-6206, 2014.

19. Hu T, Wu Z, Vervelde L, Rothwell L, Hume DA and Kaiser P: Functional annotation of the T-cell immunoglobulin mucin family in birds. Immunology 148: 287-303, 2016.

20. Xu G, Zheng K, Lu X, Wang J, Chai Y and Wang J: Association between polymorphisms in the promoter region of T cell immunoglobulin and mucin domain-3 and myasthenia gravis-associated thymoma. Oncol Lett 9: 1470-1474, 2015.

21. Angiari S and Constantin G: Regulation of $\mathrm{T}$ cell trafficking by the $\mathrm{T}$ cell immunoglobulin and mucin domain 1 glycoprotein. Trends Mol Med 20: 675-684, 2014.

22. Ju Y, Hou N, Meng J, Wang X, Zhang X, Zhao D, Liu Y, Zhu F, Zhang L, Sun W, et al: T cell immunoglobulin- and mucin-domain-containing molecule-3 (Tim-3) mediates natural killer cell suppression in chronic hepatitis B. J Hepatol 52: 322-329, 2010.

23. Ding Q, Yeung M, Camirand G, Zeng Q, Akiba H, Yagita H, Chalasani G, Sayegh MH, Najafian N and Rothstein DM: Regulatory B cells are identified by expression of TIM-1 and can be induced through TIM-1 ligation to promote tolerance in mice. J Clin Invest 121: 3645-3656, 2011.

24. Xiao S, Brooks CR, Sobel RA and Kuchroo VK: Tim-1 is essential for induction and maintenance of IL-10 in regulatory B cells and their regulation of tissue inflammation. J Immunol 194: 1602-1608, 2015.

25. Xu J, Jiang P and Liu J: Pooled-analysis of the association between TIM-1 5383_5397 insertion/deletion polymorphism and asthma susceptibility. Mol Biol Rep 41: 7825-7831, 2014.

26. Li M, Ablan SD, Miao C, Zheng YM, Fuller MS, Rennert PD, Maury W, Johnson MC, Freed EO and Liu SL: TIM-family proteins inhibit HIV-1 release. Proc Natl Acad Sci USA 111: E3699-E3707, 2014.

27. Chou FC, Kuo CC, Chen HY, Chen HH and Sytwu HK: DNA demethylation of the TIM-3 promoter is critical for its stable expression on T cells. Genes Immun 17: 179-186, 2016.

28. Cai XZ, Huang WY, Qiao Y, Chen Y, Du SY, Chen D, Yu S, Liu N, Dou LY and Jiang Y: Downregulation of TIM-3 mRNA expression in peripheral blood mononuclear cells from patients with systemic lupus erythematosus. Braz J Med Biol Res 48: 77-82, 2015.

29. Shan NN, Hu Y, Hou M, Gao J, Wang X, Liu X and Li Y: Decreased Tim-3 and its correlation with Th1 cells in patients with immune thrombocytopenia. Thromb Res 133: 52-56, 2014. 
30. Lee MJ, Woo MY, Heo YM, Kim JS, Kwon MH, Kim K and Park S: The inhibition of the T-cell immunoglobulin and mucin domain 3 (Tim3) pathway enhances the efficacy of tumor vaccine. Biochem Biophys Res Commun 402: 88-93, 2010.

31. Dardalhon V, Anderson AC, Karman J, Apetoh L, Chandwaskar R, Lee DH, Cornejo M, Nishi N, Yamauchi A, Quintana FJ, et al: Tim-3/galectin-9 pathway: Regulation of Th1 immunity through promotion of CD11b+Ly-6G+ myeloid cells. J Immunol 185 $1383-1392,2010$.

32. Roth CG, Garner K, Eyck ST, Boyiadzis M, Kane LP and Craig FE: TIM3 expression by leukemic and non-leukemic myeloblasts. Cytometry B Clin Cytom 84: 167-172, 2013.

33. Moller-Hackbarth K, Dewitz C, Schweigert O, Trad A, Garbers C, Rose-John S and Scheller J: A disintegrin and metalloprotease (ADAM) 10 and ADAM17 are major sheddases of T cell immunoglobulin and mucin domain 3 (Tim-3). J Biol Chem 288: 34529-34544, 2013.

34. Zhao D, Hou N, Cui M, Liu Y, Liang X, Zhuang X, Zhang Y, Zhang L, Yin D, Gao L, et al: Increased T cell immunoglobulin and mucin domain 3 positively correlate with systemic IL-17 and TNF- $\alpha$ level in the acute phase of ischemic stroke. J Clin Immunol 31: 719-727, 2011

35. M PN: World medical association publishes the revised declaration of Helsinki. Natl Med J India 27: 56, 2014.

36. Ali R, Toh HC and Chia WK; ASCOLT Trial Investigators: The utility of Aspirin in Dukes C and High Risk Dukes B Colorectal cancer-the ASCOLT study: Study protocol for a randomized controlled trial. Trials 12: 261,2011.

37. $\mathrm{Hu} \mathrm{H}$, Krasinskas A and Willis J: Perspectives on current tumor-node-metastasis (TNM) staging of cancers of the colon and rectum. Semin Oncol 38: 500-510, 2011.

38. Ma B, Qu P, Zhang XM, Zhang YF, Hu PZ, Ge W, Si SY, Huang Y, Li $X$ and Sui YF: Culturing dendritic cells from the peripheral blood with successive adherence method and observing the utralmicrostructure of cells. J Mod Oncol, 2007.

39. Forlenza M, Kaiser T, Savelkoul HF and Wiegertjes GF: The use of real-time quantitative PCR for the analysis of cytokine mRNA levels. Methods Mol Biol 820: 7-23, 2012.

40. Livak KJ and Schmittgen TD: Analysis of relative gene expression data using real-time quantitative PCR and the 2(-Delta Delta C(T)) method. Methods 25: 402-408, 2001.

41. Sun Y, Shen S, Liu X, Tang H, Wang Z, Yu Z, Li X and Wu M: MiR-429 inhibits cells growth and invasion and regulates EMT-related marker genes by targeting Onecut 2 in colorectal carcinoma. Mol Cell Biochem 390: 19-30, 2014.

42. Jayachandran R and Pieters J: Regulation of immune cell homeostasis and function by coronin 1. Int Immunopharmacol 28: 825-828, 2015.

43. Sharma R, Kapila R, Dass G and Kapila S: Improvement in Th1/Th2 immune homeostasis, antioxidative status and resistance to pathogenic E. coli on consumption of probiotic Lactobacillus rhamnosus fermented milk in aging mice. Age (Dordr) 36: 9686, 2014.

44. Freeman GJ, Casasnovas JM, Umetsu DT and DeKruyff RH: TIM genes: A family of cell surface phosphatidylserine receptors that regulate innate and adaptive immunity. Immunol Rev 235: $172-189,2010$
45. Zhang L, Ai Y and Tsung A: Clinical application: Restoration of immune homeostasis by autophagy as a potential therapeutic target in sepsis. Exp Ther Med 11: 1159-1167, 2016.

46. Rossi M and Bot A: The Th17 cell population and the immune homeostasis of the gastrointestinal tract. Int Rev Immunol 32: 471-474, 2013.

47. Takeuchi $\mathrm{Y}$ and Nishikawa $\mathrm{H}$ : Roles of regulatory $\mathrm{T}$ cells in cancer immunity. Int Immunol 28: 401-409, 2016.

48. Cabrera R, Ararat M, Xu Y,Brusko T, Wasserfall C, Atkinson MA, Chang LJ, Liu C and Nelson DR: Immune modulation of effector $\mathrm{CD} 4+$ and regulatory $\mathrm{T}$ cell function by sorafenib in patients with hepatocellular carcinoma. Cancer Immunol Immunother 62: 737-746, 2013.

49. Liu Y, Gao LF, Liang XH and Ma CH: Role of Tim-3 in hepatitis B virus infection: An overview. World J Gastroenterol 22: 2294-2303, 2016

50. Wang L, Zhao C, Peng Q, Shi J and Gu G: Expression levels of CD28, CTLA-4, PD-1 and Tim-3 as novel indicators of T-cell immune function in patients with chronic hepatitis B virus infection. Biomed Rep 2: 270-274, 2014

51. Cai C, Xu YF, Wu ZJ, Dong Q, Li MY, Olson JC, Rabinowitz YM, Wang LH and Sun Y: Tim-3 expression represents dysfunctional tumor infiltrating T cells in renal cell carcinoma. World J Urol 34: 561-567, 2016.

52. da Silva IP, Gallois A, Jimenez-Baranda S, Khan S, Anderson AC, Kuchroo VK, Osman I and Bhardwaj N: Reversal of NK-cell exhaustion in advanced melanoma by Tim-3 blockade. Cancer Immunol Res 2: 410-422, 2014.

53. Cheng YQ, Ren JP, Zhao J, Wang JM, Zhou Y, Li GY, Moorman JP and Yao ZQ: MicroRNA-155 regulates interferon-gamma production in natural killer cells via Tim-3 signalling in chronic hepatitis C virus infection. Immunology 145: 485-497, 2015.

54. Fu X, Wu B, Huang B, Zheng H, Huang S, Gan Y, Shen J, Lun ZR and $\mathrm{Lu} \mathrm{F}$ : The correlation of Tim-3 and IFN- $\gamma$ expressions in mice infected with Toxoplasma gondii during gestation. Parasitol Res 114: 125-132, 2015.

55. Charwat V, Rothbauer M, Tedde SF, Hayden O, Bosch JJ, Muellner P, Hainberger R and Ertl P: Monitoring dynamic interactions of tumor cells with tissue and immune cells in a lab-on-a-chip. Anal Chem 85: 11471-11478, 2013.

56. Bose T and Trimper S: Noise-assisted interactions of tumor and immune cells. Phys Rev E Stat Nonlin Soft Matter Phys 84: 021927, 2011.

57. Mazer B: Is there a place for B cells as regulators of immune tolerance in allergic diseases? Clin Exp Allergy 44: 469-471, 2014.

58. Gao X, Yang J, He Y and Zhang J: Quantitative assessment of TIM-3 polymorphisms and cancer risk in Chinese Han population. Oncotarget 7: 35768-35775, 2016. 